\title{
Determinação da Digestibilidade da Matéria Seca e da Proteína Bruta do Fubá de Milho e do Farelo de Soja para Tambaqui (Colossoma macropomum), Utilizando-se Técnicas com Uso de Indicadores Internos e Externos ${ }^{1}$
}

\author{
Manuel Vazquez Vidal Jr.2 , Juarez Lopes Donzele³, Dálcio Ricardo de Andrade ${ }^{4}$, Luiz Carlos \\ dos Santos ${ }^{5}$
}

\begin{abstract}
RESUMO - Foram realizados dois experimentos com o objetivo de comparar técnicas de digestibilidade de nutrientes de alimentos para peixes, com o uso dos indicadores externos (óxido crômico e carbonato de bário) e internos (cinza insolúvel em ácido, cinza insolúvel em detergente ácido, fibra bruta e fibra detergente ácido) e com a técnica de determinação direta. Tambaquis com $100 \mathrm{~g}$ receberam, no primeiro experimento, fubá de milho e, no segundo, farelo de soja. O óxido crômico e o carbonato de bário são indicadores externos efetivos para estimar os coeficientes de digestibilidade dos alimentos para tambaquis. A fibra bruta e a fibra detergente ácido apresentaram baixa recuperação e não estimaram de forma consistente os coeficientes de digestibilidade dos alimentos para tambaquis, subestimando-os. A cinza insolúvel em ácido e a cinza insolúvel em detergente ácido apresentaram alta porcentagem de recuperação e estimaram de forma consistente os coeficientes de digestibilidade dos alimentos para tambaquis, quando presentes no alimento em teores acima de 3,8\% e 3,1\%, respectivamente. A técnica de determinação direta foi eficiente para estimar os coeficientes de digestibilidade dos alimentos para tambaquis.
\end{abstract}

Palavras-chave: aqüicultura, digestibilidade, nutrição, tambaqui

\section{Determination of the Digestibility of Tambaqui (Colossoma macropomum) Food Nutrients by the Techniques with Internal and External Indicators}

\begin{abstract}
Two experiments were carried out aiming to compare techniques of digestibility of fish food nutrients, by using external indicators (chromic oxide and barium carbonate), internal indicators (HCl-insoluble ash, acid detergent insoluble ash, crude fiber and acid detergent fiber) and the direct determination technique. Corn meal was used in the first experiment and soybean meal was used in the second one; both used $100 \mathrm{~g}$ tambaquis. Chromic oxide and barium carbonate are effective external indicators for estimating the digestibility coefficients of feedstuffs fed to tambaquis. Crude fiber and the acid detergent fiber present a low recovery and do not estimate accurately the digestibility coefficients of feedstuffs for tambaquis and also underestimate them. The insoluble ash in acid and the insoluble ash in detergent acid showed high recovery percentage and accurately estimated the digestibility coefficients of feedstuffs fed to tambaquis, when showed contents higher than 3.8 and 3.1, respectively. The direct determination technique was efficient to estimate the digestibility coefficients of the food given to the tambaquis.
\end{abstract}

Key Words: aquaculture, digestibility, nutrition, tambaqui

\section{Introdução}

O Brasil possui imenso potencial para a piscicultura, tanto pela sua condição edafoclimática quanto pelo elevado número de propriedades rurais que possuem área inundada para piscicultura. Além disso, o país dispõe de espécies nativas com grande potencial para produção de carne.

Entre as espécies com grande potencial para piscicultura sustentável, pode-se destacar o tambaqui, que possui elevada eficiência na conversão de proteína dietética em peso corporal e em proteína depositada no tecido muscular (Doria \& Leonhardt, 1993; Zaniboni Filho \& Meurer, 1997). Além disso, o tambaqui apresenta elevada atividade da enzima amilase (Kohla et al., 1992), o que pode explicar a sua capacidade de utilização de proteína vegetal em substituição à proteína animal (Hernández et al., 1995; Cruz et al., 1997; Silva et al., 1997) e possibilitar a redução no custo de produção desta espécie.

A produção brasileira de tambaqui no período de 1995 a 1997 passou de 2.330 para 5.580 t, o que,

\footnotetext{
1 Apoio CNPq e FAPERJ.

2 Professor visitante UENF/CCTA. E.mail: mvidal@uenf.br

3 Professor titular UFVIDZO. E.mail: donzele@ufv.br

4 Professor titular UENF/CCTA. E.mail: dalcio@uenf.br

5 Professor adjunto UFV/DBA. E.mail: Icsantos@ufv.br
} 
segundo a FAO (1999), representa mais de 65\% da produção brasileira de caracídeos.

Contribui para o ainda pequeno desenvolvimento da cadeia produtiva dessa espécie a inexistência de frigoríficos especializados. Entretanto, Viegas (1999) cita que a diversificação dos produtos processados permitirá a inclusão de espécies que, assim como o tambaqui, possuem espinhas intramusculares.

Um aspecto que torna o tambaqui uma espécie promissora é o alto rendimento (70 a 72\%) do principal corte comercial, que, geralmente, é comercializado em duas partes - com e sem espinho (Ruivo, 1998).

Apesar de Carneiro (1981) ter determinado a digestibilidade da PB de rações, a literatura a esse respeito é escassa e os diversos aspectos dos métodos de determinação da digestibilidade não foram estudados para esta espécie.

O método direto foi citado por alguns autores como sendo trabalhoso e impreciso (Nose, 1960; De Silva, 1985; Nunes, 1996). O uso de indicadores externos inertes possibilita a utilização de água corrente, uma vez que as perdas de fezes podem ser calculadas, proporcionando significativa redução no estresse (Klontz, 1995).

$\mathrm{O}$ indicador externo mais utilizado tem sido o óxido de cromo, porém existem críticas ao seu uso, pois causa aumento na eficiência de utilização dos carboidratos (Urbinati et al., 1998), o que eleva a atividade da fosfofrutoquinase, além de poder ser absorvido em pequenas concentrações (Shiau \& Liang, 1995). Em alguns casos mais raros, observou-se intoxicação por cromo; nesta situação, os peixes (Colisa fasciatus) apresentaram lesões nas branquias e nos testículos, além de produção excessiva de muco (epitelial) e aumento do lactato no sangue (Nath \& Kumar, 1987, 1988).

Outros indicadores externos, principalmente óxidos de metais trivalentes, têm sido utilizados em ensaios de digestibilidade com peixes, destacando-se o itrio (Y), o itérbio (Yb), o disprósio (Dy) e o lantânio (La) (Austreng et al., 2000; Nordrum et al., 2000). Outros compostos - ferrito de magnésio (Ellis \& Smith, 1984) e carbonato de bário (Riche et al., 1995) também têm sido utilizados.

O uso de indicadores internos tem sido proposto, por ser um método que causa menor interferência sobre os resultados e que permite estimar a quantidade de alimento ingerido, porém, é necessário que o composto seja totalmente indigestível, não seja endógeno ao peixe e esteja presente no alimento em quantidades que permitam sua fácil detecção pelos métodos analíticos. Entre os indicadores internos mais promissores, podem ser citados a cinza insolúvel em ácido ou em detergente ácido, a fibra bruta e a fibra em detergente ácido (Lied et al., 1982; De Silva, 1985; Nordrum et al., 2000).

O conhecimento da digestibilidade dos alimentos proporciona maior eficiência de sua utilização e menor impacto ambiental da atividade piscícola, uma vez que permitirá a redução nas quantidades de nutrientes excretados. Diversos fatores afetam a determinação da digestibilidade dos alimentos e das rações, destacando-se o tipo de marcador.

Conduziu-se esta pesquisa com os objetivos de avaliar e comparar o uso dos indicadores externos (óxido crômico e carbonato de bário), com o de indicadores internos (cinza insolúvel de ácido, cinza insolúvel em detergente ácido, fibra bruta e fibra detergente ácido) e a técnica de determinação direta.

\section{Material e Métodos}

Dois experimentos foram realizados na Estação de Hidrobiologia e Piscicultura do Departamento de Biologia Animal da Universidade Federal de Viçosa.

No primeiro experimento, o alimento-teste foi o fubá de milho. Foram utilizados 36 tambaquis com peso médio de $95 \mathrm{~g}( \pm 1,4 \mathrm{~g})$, alojados em 12 aquários de estudos metabólicos, semelhantes aos descritos pelo sistema Guelph, com 20 L de capacidade efetiva, com recipiente para coleta de fezes por decantação.

Os peixes foram distribuídos por peso nos 12 aquários; determinando-se, por sorteio, quatro aquários com peixes receberiam alimento com $1 \%$ de óxido crômico, quatro com peixes que receberiam alimento com $0,5 \%$ de carbonato de bário e quatro com peixes recebendo alimento sem indicador externo, porém com quantidades pre-determinadas de fibra bruta (FB), fibra em detergente ácido (FDA), cinza insolúvel em ácido (CIA) e cinza insolúvel em detergente ácido (CIDA); nestes últimos aquários, as fezes foram coletadas na sua totalidade, permitindo a utilização da técnica direta de determinação de digestibilidade.

O delineamento experimental foi o inteiramente casualizado, com sete tratamentos (óxido de cromo $1 \%$, carbonato de bário $0,5 \%$, fibra bruta, fibra em detergente ácido, cinza insolúvel em ácido, cinza insolúvel em detergente ácido e coleta total de fezes), quatro repetições e três peixes por aquário (unidade experimental). 
No segundo experimento, foram utilizados 36 tambaquis com $104 \mathrm{~g}$ de peso médio. As instalações foram as mesmas utilizadas no experimento 1 . O delineamento experimental foi idêntico ao do anterior, variando apenas o alimento, que passou a ser o farelo de soja.

Visando a obtenção dos valores de produção de nitrogênio e matéria seca endógenos, necessários para correção dos coeficientes de digestibilidade, foi realizado ensaio prévio. Neste ensaio, os animais receberam glicose e foi realizada a coleta total das fezes por um período de 48 horas. A glicose foi administrada pura, por via oral, com auxílio de uma seringa e um cateter que era introduzido até o esôfago. $\mathrm{O}$ uso de glicose durante o período de coleta visou minimizar o catabolismo protéico, o que poderia vir a gerar valores superestimados de nitrogênio endógeno.

Os aquários foram dotados de fluxo contínuo de ar, proveniente de compressores elétricos. O difusor adotado foi pedras porosas cilíndricas, colocadas a $10 \mathrm{~cm}$ de profundidade. A cada 12 horas, foi monitorada a concentração de oxigênio dissolvido, com o auxílio de oxímetro digital.

Para manutenção da temperatura em $30^{\circ} \mathrm{C}$, foram utilizados termostatos de lâmina metálica, acoplados a aquecedores. A temperatura da água foi monitorada a cada 2 horas, com termômetros de bulbo de mercúrio.

A cada 8 horas, imediatamente após a coleta de fezes, foi realizada a renovação de 33\% do volume da água de cada aquário, devendo-se ressaltar que a água reposta possuía a mesma temperatura da água do aquário. Para tanto, foram utilizadas caixas dotadas de aquecedores e termostatos, para manter a água na temperatura desejada.
Em ambos os experimentos, o regime de iluminação adotado foi de 12 horas de luz e 12 horas de escuro, proveniente de luz natural, associada a lâmpadas fluorescentes.

Os peixes, distribuídos nos aquários experimentais, foram mantidos durante 48 horas em ambiente com temperatura a $30^{\circ} \mathrm{C}$, para adaptação às instalações. Neste período, foi fornecida uma dieta composta de $50 \%$ de ração comercial (28\% de PB e $3.100 \mathrm{kcal} / \mathrm{kg}$ ) $25 \%$ de fubá de milho e $25 \%$ de farelo de soja, para adaptação aos alimentos-teste e verificação do consumo voluntário. Após esse período, os peixes foram submetidos a jejum de 36 horas, visando o esvaziamento do tubo digestivo, para que a dieta de adaptação não interferisse na próxima fase. Em seguida, o alimento, previamente peletizado, foi oferecido puro e sua quantidade foi precisamente 90\% do consumo voluntário (aproximadamente 8\% do peso vivo), em uma única refeição, introduzida diretamente no esôfago com o auxílio de um tubo de vidro esmerilhado e um bastão também de vidro.

Consta na Tabela 1 a composição dos alimentosteste e da ração adaptativa.

As fezes foram coletadas a cada 30 minutos, durante 48 horas, e, após a coleta, foram acondicionadas em sacos plásticos, identificados e armazenados em freezer, para posterior análise das fezes. O volume de fezes permitiu a realização das análises de matéria seca, proteína, CIA e CIDA.

Ao final da coleta total, as fezes, correspondentes a uma mesma unidade experimental, foram homogeneizadas, identificadas e encaminhadas ao Laboratório de Nutrição Animal do Departamento de Zootecnia da Universidade Federal de Viçosa, para determinação da matéria seca e da proteína bruta. No

Tabela 1 - Valores de matéria seca (MS), proteína bruta (PB), fibra em detergente ácido (FDA), fibra bruta (FB), cinza insolúvel em ácido (CIA) e da cinza insolúvel em detergente ácido (CIDA) do fubá de milho, do farelo de soja e da ração de adaptação

Table 1 - Values of dry matter (DM), crude protein (CP), acid detergent fiber (ADF), crude fiber (CF), acid insoluble ash (AIA) and acid detergent insoluble ash (ADIA) of corn starch, soybean meal and adaptation ration

\begin{tabular}{|c|c|c|c|c|c|c|}
\hline $\begin{array}{l}\text { Alimento } \\
\text { Feedstuff }\end{array}$ & $\begin{array}{c}\text { MS (\%) } \\
\text { DM }\end{array}$ & $\begin{array}{c}\mathrm{PB}(\%) \\
C P\end{array}$ & $\begin{array}{c}\text { FDA (\%) } \\
A D F\end{array}$ & $\begin{array}{c}\mathrm{FB}(\%) \\
\mathrm{CF}\end{array}$ & $\begin{array}{c}\text { CIA (\%) } \\
\text { AIA }\end{array}$ & $\begin{array}{c}\text { CIDA (\%) } \\
\text { ADIA }\end{array}$ \\
\hline $\begin{array}{l}\text { Fubá de milho } \\
\text { Corn starch }\end{array}$ & 87,02 & 8,57 & 3,27 & 1,89 & 0,91 & 0,84 \\
\hline $\begin{array}{l}\text { Farelo de soja } \\
\text { Soybean meal }\end{array}$ & 87,91 & 45,37 & 7,56 & 5,74 & 3,76 & 3,09 \\
\hline $\begin{array}{l}\text { Ração adaptativa } \\
\text { Adaptation ration }\end{array}$ & 89,01 & 27,39 & 5,39 & 2,78 & 1,78 & 1,66 \\
\hline
\end{tabular}

${ }^{1}$ Valor determinado (Determined value).

R. Bras. Zootec., v.33, n.6, p.2193-2200, 2004 (Supl. 3) 
mesmo laboratório, foram realizadas a análise da composição bromatológica da ração adaptativa e dos alimentos testados e a determinação das concentrações dos indicadores nas fezes (AOAC, 1984; Silva, 1990).

As variáveis analisadas foram a porcentagem de recuperação do indicador e os coeficientes de digestibilidade verdadeira da matéria seca (CDvMS) e da proteína bruta (CDvPB) dos alimentos testados, segundo a fórmula:

$\mathrm{CDv}=\{[$ nut. na dieta - (nut. nas fezes $\mathrm{x}$ FI1 nut. na digesta endógeno x FI2)] x 100\}

nut. Dieta

em que Nut. = nutriente; FI1 = Indicador na dieta/ indicador na digesta; FI2 = Indicador na dieta endógeno/indicador nas fezes endógeno.

Para a técnica direta, os termos FI1 e FI2 não são considerados na fórmula.

As análises estatísticas das variáveis foram realizadas com o uso do programa SAEG - Sistema de Análises Estatísticas e Genéticas, segundo o modelo matemático:

$$
Y_{i j}=\mu+T_{i}+\varepsilon_{i j}
$$

em que $Y_{i j}=$ valor observado para a variável estudada; $\mu$ = média geral da característica; $\mathrm{T}_{\mathrm{i}}=$ efeito do tratamento $\mathrm{i}$, sendo $\mathrm{i}=$ marcador; e $\varepsilon_{\mathrm{ij}}=$ erro aleatório associado a cada observação.

Após a análise de variância, procedeu-se ao teste de Newman-Keuls, para comparação das médias obtidas.

\section{Resultados e Discussão}

A temperatura da água dos aquários permaneceu relativamente constante durante todo o período experimental. Na fase de adaptação, a temperatura média foi de $29,4 \pm 1,3^{\circ} \mathrm{C}$. No experimento em que foi utilizado fubá de milho, a temperatura média da água dos aquários experimentais foi de $30,1 \pm 0,9^{\circ} \mathrm{C}$ e no experimento com farelo de soja, de $29,7 \pm 1,1^{\circ} \mathrm{C}$. Nessa temperatura, o tempo de esvaziamento do tubo digestivo dos tambaquis foi de, aproximadamente, 25 horas, não se observando retenção dos marcadores e dos alimentos e, portanto, pode-se atribuir os valores inferiores a 100\% à absorção ou lixiviação das fezes.
O valor de oxigênio dissolvido na água foi superior a 3,9 mg/L durante todo o período experimental, nos dois experimentos. A faixa ótima de oxigênio dissolvido na água para tambaqui é de 3,0 a 6,0 mg/L (Yancey \& Menezes, 1983). Não foi observada a presença de lábios hiperemiados, que foram citados por Kohla et al. (1992) como indicação de condição de hipóxia nesta espécie.

Nesses experimentos, a concentração de oxigênio dissolvido na água, possivelmente, não contribuiu para as variações na digestibilidade dos alimentos testados, nem tampouco para a recuperação dos indicadores. De acordo com Ross et al. (1992), a concentração de oxigênio na água pode afetar os processos de digestão e de absorção de nutrientes e, em águas com níveis de oxigênio dissolvido abaixo da faixa ótima, os peixes podem ter sua capacidade de digestão dos alimentos reduzida (Pouliot \& De La Noüe, 1988; Néji \& De La Noüe, 1998).

Na Tabela 2, são apresentados os valores médios da porcentagem de recuperação dos marcadores com os alimentos testados. A perda de indicador por degradação pode resultar em valores de digestibilidade subestimados, uma vez que pode ocorrer superestimação da quantidade de fezes.

Neste experimento, os indicadores externos apresentaram, para o fubá de milho, maiores porcentagens de recuperação. Entretanto, quando o alimento-teste foi o farelo de soja, estes apresentaram porcentagem de recuperação semelhante à obtida para a CIA e a CIDA.

Esses resultados foram similares aos encontrados por Riche et al. (1995), que, ao compararem o uso destes dois indicadores na determinação da digestibilidade de alimentos pela tilápia, também não encontraram diferenças significativas na sua recuperação.

A fibra bruta e a FDA apresentaram porcentagem de recuperação significativamente inferior $(P<0,05)$ à observada com os indicadores externos, nos dois experimentos, apresentando valores próximos a 83\%. Este resultado foi semelhante ao obtido por Sharat (1993), que, comparando o uso de fibra bruta e óxido de cromo como indicadores em ensaio de digestibilidade com bagre-africano, observou que a recuperação da fibra bruta foi inferior à do óxido de cromo.

Os peixes não têm apresentado grande capacidade de digerir diversas fontes de carboidratos, por não possuírem enzimas que permitam a digestão da celulose, lignocelulose e lignina (Steffens, 1987; NRC, 
Tabela 2 - Porcentagem de recuperação dos marcadores e coeficientes de digestibilidade verdadeira da matéria seca e da proteína do fubá de milho (FM) e do farelo de soja (FS) para tambaquis

Table 2 - Percentage of markers recovery and coefficients of true digestibility of dry matter and crude protein of corn starch (CS) and soybean meal (SM) for tambaqui

\begin{tabular}{|c|c|c|c|c|}
\hline \multirow[t]{2}{*}{$\begin{array}{l}\text { Indicador } \\
\text { Marker }\end{array}$} & \multicolumn{2}{|c|}{$\begin{array}{c}\text { Porcentagem média de recuperação (\%) } \\
\text { Average recovery percentage (\%) }\end{array}$} & \multicolumn{2}{|c|}{ CV(\%) } \\
\hline & $\begin{array}{l}\text { Fubá de milho } \\
\text { Corn starch }\end{array}$ & $\begin{array}{l}\text { Farelo de soja } \\
\text { Soybean meal }\end{array}$ & $\begin{array}{l}\text { FM } \\
C S\end{array}$ & $\begin{array}{l}\text { FS } \\
S M\end{array}$ \\
\hline $\begin{array}{l}\text { Óxido de cromo }(1 \%) \\
\text { Chromium oxide }(1 \%)\end{array}$ & $95,80^{\mathrm{A}}$ & $99,07^{\mathrm{A}}$ & 7,32 & 5,92 \\
\hline $\begin{array}{l}\text { Carbonato de bário }(0,5 \%) \\
\text { Barium carbonate }(.5 \%)\end{array}$ & $98,67^{\mathrm{A}}$ & $98,97^{\mathrm{A}}$ & 6,44 & 7,11 \\
\hline $\begin{array}{l}\text { CIA } \\
\text { CIDA } \\
\text { Fibra bruta }\end{array}$ & $\begin{array}{l}88,21^{\mathrm{B}} \\
87,64^{\mathrm{B}} \\
81,24^{\mathrm{B}}\end{array}$ & $\begin{array}{l}99,71^{\mathrm{A}} \\
98,66^{\mathrm{A}} \\
82,24^{\mathrm{B}}\end{array}$ & $\begin{array}{r}9,71 \\
7,04 \\
11,06\end{array}$ & $\begin{array}{l}8,79 \\
6,25 \\
9,11\end{array}$ \\
\hline $\begin{array}{l}\text { Crude fiber } \\
\text { FDA } \\
\text { ADF }\end{array}$ & $85,47^{\mathrm{B}}$ & $84,52^{\mathrm{B}}$ & 9,72 & 8,27 \\
\hline
\end{tabular}

Médias seguidas da mesma letra na coluna são diferentes $(P<0,05)$ pelo teste Newman-Keuls.

Means followed by the same letter, within a column, are different $(P<.05)$ by Newman-Keuls test.

1993). Com base neste fato, tem-se buscado utilizar estas frações do alimento como indicadores para diversas espécies de peixes, inclusive para o tambaqui. Khola et al. (1992), trabalhando com tambaqui, determinaram a atividade enzimática das enzimas digestivas e não obtiveram qualquer evidência da capacidade do tambaqui digerir enzimaticamente esses compostos. Possivelmente, a perda de fibra bruta e de FDA está relacionada à digestão microbiana no intestino grosso, citada por Steffens (1987) para outras espécies de peixes.

A CIA e a CIDA, no experimento com tambaquis alimentados com fubá de milho, apresentaram porcentagem de recuperação significativamente inferior $(\mathrm{P}<0,05)$ à dos indicadores externos e semelhante à da fibra bruta e da FDA, porém, no experimento em que os peixes foram alimentados com farelo de soja, a CIA foi o indicador que apresentou a maior porcentagem de recuperação. Neste segundo experimento, não foi observada diferença significativa entre as porcentagens de recuperação dos indicadores externos e da CIA e da CIDA.

É provável que a elevada perda da CIA e da CIDA do fubá de milho esteja associada à sua baixa concentração neste alimento e, conseqüentemente, nas fezes provenientes dos animais que o consumiram, portanto, qualquer imprecisão na sua determinação pode resultar em grandes variações nos valores de recuperação desses indicadores.

R. Bras. Zootec., v.33, n.6, p.2193-2200, 2004 (Supl. 3)
Carvalho (1989) verificou que, em trabalhos com o uso de CIDA como indicador da digestibilidade em ruminantes, os valores de digestibilidade encontrados são semelhantes aos obtidos com uso de coleta total, a partir de concentrações de CIDA superiores a 3\% da dieta. Bureau et al. (1999) verificaram que a CIA somente deverá ser adotada com indicador quando em quantidade superior a $2,5 \%$ da dieta, para trutas.

Constam na Tabela 3 os valores médios dos coeficientes de digestibilidade verdadeira da matéria seca (CDvMS) e da proteína bruta (CDvPB) do fubá de milho e do farelo de soja.

Os coeficientes de digestibilidade verdadeira da matéria seca e da proteína bruta do farelo de soja e do fubá de milho apresentaram diferenças significativas $(\mathrm{P}<0,05)$, em função do indicador utilizado nos cálculos. Quando determinados com a técnica de coleta total de fezes, foram superiores aos citados para catfish, truta (NRC, 1993) e salmão (Storebakken et al., 2000) e próximos aos valores observados para tilápia do Nilo (NRC, 1993; Fontaínhas-Fernandes et al., 1999).

Alguns autores têm descrito que o óxido de cromo não atende aos requisitos para ser usado como indicador, por ser um nutriente essencial em dietas para tilápias (Shiau \& Lin, 1993; Shiau \& Chen, 1993) e por alterar a taxa de passagem em tilápias (Bowen, 1978) e em trutas (Dabrowski \& Dabrowska, 1981), subestimando os coeficientes de 
Tabela 3 - Coeficientes de digestibilidade verdadeira da matéria seca (CDvMS) e da proteína bruta (CDvPB) do fubá de milho e do farelo de soja para tambaquis de peso médio de aproximadamente $100 \mathrm{~g}$

Table 3 - Coefficients of true digestibility of dry matter (CDVMS) and crude protein (CDVPB) of corn starch and soybean meal for tambaqui averaging $100 \mathrm{~g}$

\begin{tabular}{|c|c|c|c|c|}
\hline \multirow[t]{3}{*}{$\begin{array}{l}\text { Indicador } \\
\text { Marker }\end{array}$} & \multicolumn{4}{|c|}{$\begin{array}{l}\text { Coeficientes de digestibilidade verdadeira e CV }(\%)^{1} \\
\text { Coefficients of true digestibility and CV }\end{array}$} \\
\hline & \multicolumn{2}{|c|}{$\begin{array}{l}\text { Fubá de milho } \\
\text { Corn starch }\end{array}$} & \multicolumn{2}{|c|}{$\begin{array}{l}\text { Farelo de soja } \\
\text { Soybean meal }\end{array}$} \\
\hline & CDvMS & CDvPB & CDvMs & CDvPB \\
\hline Óxido de cromo (1\%) & $83,29^{\mathrm{A}}(8,73)$ & $81,48^{\mathrm{A}}(7,91)$ & $82,79^{\mathrm{A}}(9,27)$ & $90,35^{\mathrm{A}}(6,41)$ \\
\hline $\begin{array}{l}\text { Chromium oxide }(1 \%) \\
\text { Carbonato de bário }(0,5 \%) \\
\text { Barium carbonate }(.5 \%)\end{array}$ & $84,10^{\mathrm{A}}(6,24)$ & $82,70^{\mathrm{A}}(5,99)$ & $83,35^{\mathrm{A}}(8,17)$ & $90,82^{\mathrm{A}}(8,31)$ \\
\hline $\begin{array}{l}\text { CIA } \\
\text { CIDA } \\
\text { Fibra bruta }\end{array}$ & $\begin{array}{l}77,93^{\mathrm{B}}(9,37) \\
76,45^{\mathrm{B}}(7,39) \\
71,82^{\mathrm{C}}(8,66)\end{array}$ & $\begin{array}{l}78,11^{\mathrm{B}}(8,73) \\
74,37^{\mathrm{B}}(8,33) \\
70,99^{\mathrm{C}}(7,59)\end{array}$ & $\begin{array}{l}82,87^{\mathrm{A}}(9,28) \\
82,56^{\mathrm{A}}(9,42) \\
73,28^{\mathrm{B}}(8,32)\end{array}$ & $\begin{array}{l}91,89^{\mathrm{A}}(9,93) \\
90,58^{\mathrm{A}}(8,65) \\
79,86^{\mathrm{B}}(8,67)\end{array}$ \\
\hline $\begin{array}{l}\text { Crude fiber } \\
\text { FDA }\end{array}$ & $75,52^{\mathrm{B}}(7,58)$ & $74,77^{\mathrm{B}}(9,44)$ & $73,76^{\mathrm{B}}(6,83)$ & $82,68^{\mathrm{B}}(9,11)$ \\
\hline $\begin{array}{l}\text { ADF } \\
\text { Coleta total sem indicador } \\
\text { Total collection without marker }\end{array}$ & $84,53^{\mathrm{A}}(6,83)$ & $82,56^{\mathrm{A}}(6,33)$ & $83,69^{\mathrm{A}}(5,77)$ & $91,89^{\mathrm{A}}(6,47)$ \\
\hline
\end{tabular}

Médias seguidas da mesma letra na coluna são diferentes $(P<0,05)$ pelo teste Newman-Keuls.

1 Os valores entre parênteses referem-se ao coeficiente de variação, em porcentagem.

Means followed by the same letter, within a column, are different $(P<.05)$ by Newman-Keuls test.

${ }^{1}$ The values within parenthesis refer to the coefficient of variation, in percentage.

digestibilidade. Os resultados obtidos com tambaquis, nesta pesquisa, não corroboram os descritos por esses autores.

Embora não tenha ocorrido diferença $(\mathrm{P}>0,05)$ entre as porcentagens de recuperação dos indicadores externos, com o carbonato de bário, verificaram-se maiores valores absolutos para os coeficientes citados. Resultados semelhantes foram descritos, para trutas, por Riche et al. (1995), e provavelmente essa diferença pode ser explicada por sua menor solubilidade em água, quando comparado ao óxido de cromo.

A utilização da fibra bruta e da FDA como indicadores externos resultou em valores de CDvMS e de $\mathrm{CDvPB}$ menores $(\mathrm{P}<0,05)$ que os obtidos com a técnica de determinação direta ou com uso de indicadores externos, o que pode ter ocorrido em função da baixa recuperação destes indicadores. Resultados diferentes foram encontrados por Morales et al. (1999), que, em experimento de digestibilidade com trutas, obtiveram resultados de coeficiente de digestibilidade da matéria seca e da proteína similares quando foi utilizado o óxido crômico ou a fibra bruta como indicador inerte.
Aparentemente, o uso da fibra bruta e da FDA como indicador deve ser restrito a espécies com tubo digestivo curto. Esta idéia é reforçada pelo fato de De Silva (1985) ter obtido resultados baixos e inconsistentes dos coeficientes de digestibilidade determinados com uso da fibra bruta, como indicador inerte em tilápias, que, assim como os tambaquis, são peixes que possuem o tubo digestivo relativamente longo, podendo apresentar degradação microbiana da fibra bruta no intestino grosso.

A CIA e a CIDA presentes no farelo de soja estimaram o CDvMS e o CDvPB de forma similar à técnica de determinação direta, indicando que estas frações podem ser utilizadas como indicador inerte, desde que em concentrações iguais ou superiores a 3,8 e 3,1\%, respectivamente. Quando o alimento utilizado foi o fubá de milho, esses indicadores não estimaram os coeficientes de forma consistente, subestimando-os, possivelmente, por causa de sua baixa concentração neste alimento. A baixa recuperação de CIA e CIDA do fubá de milho e a conseqüente estimação incorreta dos coeficientes não parecem estar relacionadas ao binômio absorção:lixiviação. 


\section{Conclusões}

O óxido crômico e o carbonato de bário são indicadores externos efetivos para estimar os coeficientes de digestibilidade dos alimentos para tambaquis.

A fibra bruta e a fibra em detergente ácido apresentaram baixa recuperação e não estimaram de forma consistente os coeficientes de digestibilidade dos alimentos para tambaqui, subestimando-os.

A cinza insolúvel em ácido e a cinza insolúvel em detergente ácido mostraram ter alta porcentagem de recuperação e estimaram de forma consistente os coeficientes de digestibilidade dos alimentos para tambaqui, quando presentes no alimento em teores acima de 3,8 e 3,1\%, respectivamente.

A técnica de determinação direta mostrou-se eficiente para estimar os coeficientes de digestibilidade dos alimentos para tambaqui.

\section{Literatura Citada}

ASSOCIATION OF OFFICIAL AGRICULTURAL CHEMISTS - AOAC. Official method of analysis. 14.ed. Washington, D.C.: 1984. 1141p.

AUSTRENG, E.; STOREBAKKEN, T.; THOMASSEN, M.S. et al. Evaluation of selected trivalent metal oxides as inert markers used to estimate apparent digestibility in salmonids. Aquaculture, v.188, n.1-2, p.65-78, 2000.

BOWEN, S.H. Chromic acid in assimilation studies - a caution. Transaction American of Fisheries Society, v.107, n.5, p.755-756, 1978.

BUREAU, D.P.; HARRIS, A.M.; CHO, C.Y. Apparent digestibility of rendered animal protein ingredients for rainbow trut (Oncorhynchus mykiss). Aquaculture, v.180, n.3-4, p.345-358, 1999.

CARNEIRO, D.J. Digestibilidade protéica em dietas isocalóricas para o tambaqui, Colossoma macropomum (Cuvier, Pisces). In: SIMPÓSIO BRASILEIRO SOBRE AQUICULTURA, 2., 1980, Jaboticabal. Anais... Brasília: SUDEPE, 1981. p.78-80.

CARVALHO, F.F.R. Efeitos de diferentes níveis de proteína bruta para cabras em lactação e uso de indicadores internos para estimar a digestibilidade dos nutrientes. Viçosa, MG: Universidade Federal de Viçosa, 1989. 72p. Dissertação (Mestrado em Zootecnia) - Universidade Federal de Viçosa, 1989.

CRUZ, W.D.; MIGUEL, C.B.; BONIFÁCIO, A.D. et al. Resíduo de cervejaria na alimentação de tambaqui, Colossoma macropomum (Cuvier,1818). Boletim do Instituto de Pesca, v.24(especial), p.133-138, 1997.

DABROWSKI, K.; DABROWSKA, H. Digestion of protein by rainbow trout (Salmo gairdneri Rich.) and absorption of amino acids within the alimentary tract. Compendium Biochemical Physiology, v.69A, n.1, p.99-111, 1981.

De SILVA, S.S. Evaluation of the use of internal and external markers in digestibility studies. In: CHO, C.Y. (Ed.) Finfish nutrition in Asia, methodological approaches to research and development. 1.ed. Ottawa: Int. Dev. Research Center, 1985. p.96-102.

DORIA, C.R.C.; LEONHARDT, J.H. Análise do crescimento de Piaractus mesopotamicus e Colossoma macropomum (Pisces: Caracidae) em sistema semi-intensivo de policultivo com arraçoamento e adubação orgânica. Revista Unimar, v.15(suplemento), p.211-222, 1993.

ELLIS, R.W.; SMITH, R.R. Determining fat digestibility in trout using a metabolic chamber. The Progressive Fish-Culturist, v.46, n.2, p.116-119, 1984.

FOOD AGRICULTURE ORGANIZATION OF THE UNITED NATIONS - FAO. Aquaculture production statistcs. 19881997. Fishery information, data and statistics unit. FAO Fisheries Circular No. 815, Revision 11, Rome, 1999. 203p.

FONTAIINHAS-FERNANDES, A.; GOMES, E.; REISHENRIQUES, M.A. et al. Replacement of fish meal by plant proteins in diet of nile tilapia: digestibility and growth performance. Aquaculture Institute, v.7, n.1, p.57-68, 1999.

HERNÁNDEZ, M.; TAKEUCHI, T.; WATANABE, T. Effect of dietary energy sources on the utilization of protein by Colossoma macropomum fingerlings. Fisheries Science, v.61, n.3, p.507-511, 1995.

KLONTZ, G.W. Care of fish in biological research. Journal of Animal Science, v.73, n.11, p.3485-3492, 1995.

KOHLA, U.; SAINT-PAUL, U.; FRIEBE, J. et al. Growth, digestive enzyme activities and hepatic glycogen levels in juvenile Colossoma macropomum Curvier from South America during feeding, starvation and refeeding. Aquaculture Fisheries Management, v.23, n.1, p.189208, 1992.

LIED, E.; JULSHAMN, K.; BRAEKKAN, O.R. Determination of protein digestibility in atlantic cod (Gadus morhua) with internal and external indicators. Canadian Fisheries Aquaculture Science, v.39, n.6, p.854-861. 1982.

MORALES, A.E.; CARDENETE, G.; SANZ, A. et al. Re-evaluation of crude fibre and acid-insoluble ash as inert markers, alternative to chromic oxide, in digestibility studies with rainbow trout (Oncorhynchus mykiss). Aquaculture, v.179, n.1-4, p.71-79, 1999.

NATIONAL RESEARCH COUNCIL - NRC. Nutrient requirements of fish. 1.ed. Washington. D.C., 1993.114p.

NATH, K.; KUMAR, N. Effect of hexavalent chromium on the carbohydrate metabolism of a freshwater tropical teleost Colisa fasciatus. Bulletin Institute Zoology Academy Science, v.26, n.2, p.245-248, 1987.

NATH, K.; KUMAR, N. Hexavalent chromium: toxicity and its impact on certain aspects of carbohydrate metabolism of a freshwater tropical teleost Colisa fasciatus. Science Total Environment, v.72, n.1, p.175-181, 1988.

NÉJI, H.; DE LA NOÜE, J. Effect of animal and vegetal protein diets on feed intake and apparent digestibility of nutrients in rainbow trout (Oncorhynchus mykiss) infected by Aeromonas salmonicida, with and without chronic hipoxia stress. Canadian Journal Fisheries Aquatic Science, v.55, n.9, p.2019-2027, 1998.

NORDRUM, S.; KROGDAHL, A.; ROSJO, C. et al. Effects of methionine, cysteine and medium chain triglygerides on nutrient digestibility, absorption of amino acids along the intestinal tract and nutrient retention in atlantic salmon (Salmo salar L.) under pair-feeding regime. Aquaculture, v.186, n.3-4, p.341-360, 2000.

R. Bras. Zootec., v.33, n.6, p.2193-2200, 2004 (Supl. 3) 
NOSE, T. On the effective value of freshwater green algae, Chllorella ellipsoidea, as a nutritive source to gold fish. Bulletin Fresh Fisheries Research Laboratory, v.10, n.1, p.1-10, 1960.

NUNES, C.S. Avaliação do valor nutricional de fontes de proteína. II - Metodologia in vivo aplicável aos animais monogástricos e aos teleósteos. Revista Portuguesa Ciências Veterinarias, v.91, n.519, p.144-151, 1996.

POULIOT, T.; DE LA NOÜE, J. Apparent digestibility in rainbow trout (Salmo gairdneri): influence of hipoxia. Canadian Journal Fisheries Aquatic Science, v.45, n.11, p.2003-2009, 1988.

RICHE, M.; WHITE, M.R.; BROWN, P.B. Barium carbonate as an alternative indicator to chromic oxide for use in digestibility experiments with rainbow trout. Nutrition Research, v.15, n.9, p.1323-1331, 1995.

ROSS, L.G.; McKINNEY, R.W.; CARDWELL, S.K. et al. The effects of dietary protein content, lipid content and ration level on oxygen consumption and specific dynamic action in Oreochromis niloticus L. Compedium Biochemical Physiology, v.10A, n.3, p.573-578, 1992.

RUIVO, U.E. Introdução aos princípios de industrialização de pescados de águas interiores. In: SEMINÁRIO DE PISCICULTURA DA ZONA DA MATA MINEIRA, 1., 1997, Muriaé. Anais... Viçosa, MG: EPAMIG, 1998. p.33-44.

SHARAT, T.M. Digestibility determination in nile catfish fingerlings using internal and external markers. Vet. Med. Journal Giza, v.41, n.3, p.83-91, 1993.

SHIAU, S.Y.; CHEN, M.J. Carbohydrate utlilization by tilapia (Oreochromis niloticus x O. aureus), as influenced by different chromium sources. Journal Nutrition, v.123, n.10, p.1747-1753, 1993.

SHIAU, S.Y.; LIANG, H.S. Carbohydrate utilization and digestibility by tilapia (Oreochromis niloticus x O. aureus), are affected by chromic oxide inclusion in diet. Journal of Nutrition, v.125, n.4, p.976-982, 1995.

SHIAU, S.Y.; LIN, S.F. Effect of supplemental ditery chromium and vanadium on the utilization of different carbohydrates in tilapia (Oreochromis niloticus x O. aureus). Aquaculture, v.110, n.3-4, p.312-330, 1993.
SILVA, D.J. Análise de alimentos (métodos químicos e biológicos). 2.ed. Viçosa, MG: Universidade Federal de Viçosa, 1990. 165p.

SILVA, P.C.; FRANÇA, A.F.S.; PADUA, D.M.C. et al. Milheto (Pennisetum americanum) como substituto do milho (Zea mays) na alimentação do tambaqui (Colossoma macropomum). Boletim Instituto Pesca, v.24(especial), p.125-131, 1997.

STEFFENS, W. Princípios fundamentales de la alimentacion de los peces. 1.ed. Zaragoza: Acribia, 1987. 275p.

STOREBAKKEN, T.; SHEARER, K.D.; BAEVERFJORD, G. et al. Digestibility of macronutrients, energy and amino acids, absorption of elements and absence of intestinal enteritis in atlantic salmon, Salmo salar, fed diets with wheat gluten. Aquaculture, v.184, n.1-2, p.115-132, 2000.

URBINATI, E.C.; SILVA, B.F.; BORGES, R. et al. Inclusão de cromo e vanádio para melhorar o aproveitamento de carboidrato da dieta do pacu, Piaractus mesopotamicus. Aquicultura Brasil’ 1998. Resumos... Recife: Simbraq, 1998. p.153.

VIEGAS, E.M.M. Situação atual e perspectivas do beneficiamento e processamento do pescado produzido em criações comerciais. In SIMPÓSIO SOBRE MANEJO E NUTRIÇÃO DE PEIXES, 3., 1999, Campinas. Anais... Campinas. Colégio Brasileiro de Nutrição Animal, 1999. p.15-24.

YANCEY, D.R.; MENEZES, J.R.R. Manual de criação de peixes. 1.ed. Campinas: Instituto Campineiro de Ensino Agrícola, 1983. 117p.

ZANIBONI FILHO, E.; MEURER, S. Limitações e potencialidades do cultivo de tambaqui (Colossoma macropomum Cuvier, 1818) na região subtropical do Brasil. Boletim Instituto Pesca, v.24(especial), p.169-172, 1997.

Recebido em: 12/09/03

Aceito em: 02/06/04 